\title{
SOLAR BATTERY CHARGERS FOR NIMH BATTERIES
}

\author{
Flemy Elizabeth Oommen ${ }^{1}$, Srinivasan $\mathrm{S}^{2}$ \\ 1, ${ }^{2}$ Hindustan Institute of Technology and Science ,Chennai \\ Email:1 ${ }^{1}$ flem2687@gmail.com, ${ }^{2}$ ssrinivasan@ hindustanuniv.ac.in
}

\section{Abstract}

\begin{abstract}
Recent technological developments in thin film photovoltaic such as amorphous silicon and hybrid dye sensitized /PV cells are leading to consumer portable solar arrays. These new arrays are lightweight, durable, flexible and achieve power efficiencies of up to $10 \%$. Already, commercial-of-the-shelf arrays exist that have panels embedded in fabric that can be folded to dimensions of less than $12^{\prime \prime} \times 12^{\prime \prime}$, yet are able to produce up to 50 Watts of power at $12 \mathrm{~V}$. Older solar battery chargers were primarily developed to recharge gel cell and lead acid batteries. This project proposes new solar battery chargers for NiMH batteries. In parallel with these developments, NiMH and Li-ion batteries are increasingly being used to power various equipment. Currently, the military is field testing solar charging of its batteries with portable solar arrays. However, so far, all known charge control algorithms have failed as they commonly falsely detect overcharge at random times in the charging and leave the battery partially charged. Here, the origins of failure in existing charge control algorithms are studied and adequate algorithms are proposed that would improve the battery charging. Additionally, ways to optimize the generated photovoltaic power is critical for portable solar application as the energy produced is limited. It is known that the use of a DC-DC converter between the solar panel and the load allows optimization of the power delivered by the solar panel when "Maximum Power Point Tracking is utilized. To increase charge speed, a maximum power point tracker is also implemented within the micro-controller of the proposed charger.
\end{abstract}

Index Terms: Charger, PV Pannel, NiMH Battery, Pertutb \& Observe method

\section{INTRODUCTION}

Older solar battery chargers (for RV's and boats) were primarily developed to recharge gel cell and lead acid batteries. However, since the emergence of these flexible and foldable solar arrays, there has become a need to develop solar battery chargers for more portable batteries, such as $\mathrm{NiMH}$ and/or Li-ion batteries that can be carried by hikers.

The solar cell panel is connected directly to the battery. At high insulation conditions, solar cells generate a voltage high enough to charge batteries. However, if the solar cell voltage is lower than the battery voltage, the charging current will be zero as blocked by the diode. The utilization of solar energy by this direct battery charger is limited under low insolation conditions necessitating an improvement to solar battery chargers at these conditions. Step-up dc choppers can increase the output voltage to a sufficient level to charge the battery, by storing magnetic energy in an inductor and then releasing it to the load (i.e. the battery) through control of a semiconductor device such as a transistor or an MOSFET. However, step-up choppers need relatively high current through an inductor in order to store sufficient magnetic energy for battery charging, which is difficult for the solar cells to provide due to their high internal impedance at low insolation. DC to DC converters allow the charge current to be reduced continuously in such a way that the resulting battery voltage is maintained at a specified value.

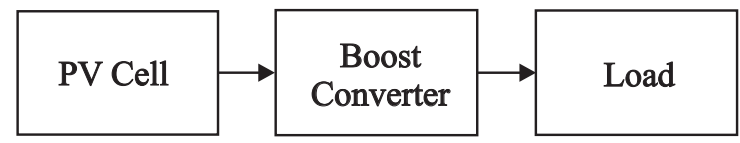

Fig. 1 Block diagram

\section{EXISTING CHARGE CONTROL ALGORITHM}

The charge transfer equation of a NiMH cell is given by:

Positive electrode:

$$
\mathrm{Ni}(\mathrm{OH})_{2}+\mathrm{OH}^{-} \Leftrightarrow \mathrm{NiOOH}+\mathrm{H}_{2} \mathrm{O}+\mathrm{e}^{-}
$$

Negative electrode:

$$
\mathrm{N}+\mathrm{H}_{2} \mathrm{O}+\mathrm{e}^{-} \Leftrightarrow \mathrm{MH}+\mathrm{OH}^{-}
$$

where $e^{-}$is a negative charge (electron).

$M$ is an intermetallic compound usually formed with a mixture of a metal and rare earth. 
Common approaches to determining when $\mathrm{NiMH}$ batteries (charged by constant current source) are fully charged rely on measuring battery terminal voltage . Occasionally, the charge process is terminated when the battery's voltage reaches a certain value. However, this is extremely unreliable and does not work when the battery is charged by different current levels or when it is placed in different ambient temperatures as the terminal voltage can be influenced widely by these conditions.

A second approach, which is more prevalent, is to stop the fast-charging process a bit after the full SOC point when the battery terminal voltage begins to drop, i.e. $d V / d t \leq K$, where $K$ is a positive fixed threshold value set by the user (around $10 \mathrm{mV}$ to 20 $\mathrm{mV}$ per cell). This is commonly implemented by specifying a $\Delta V$ drop in voltage as a threshold instead of calculating a derivative directly. However, once again, implicit in this approach is that the charging current remains constant during the charging process. This charging method is also valid for NiCd batteries. After full State Of Charge (SOC) is detected, the common method is to keep the battery charging at low current (around $0.1 \mathrm{C}$ Amps where $\mathrm{C}$ is the capacity of the battery in Amp-hours). This ensures the battery is charged to its fullest and avoids self-discharge of the battery. That method is called trickle charge. When charge time is not an issue, trickle charging can be used for the whole process. There are other charging algorithms that have been published: the overcharge is avoided by estimating the time derivative of the voltage. This approach may be more accurate, as it estimates the moment when the battery is about to enter overcharge. However, it will also subject to the same limitations as conventional algorithms when facing changing current conditions.

Another technique to detect full state of charge relies on the battery impedance changes with charging. However, in the case of NiMH chemistry, those changes are very small and require some precise model of the battery characteristics (usually involving battery history)

When the battery approaches full SOC, temperature begins to rise sharply. This is true for either NiMH or NiCd batteries. Thus, another approach to determine full SOC is to place a thermistor close to battery cells. This enables detection of charge termination when $d T / d t$ is above a threshold value. Two temperature detection methods are mainly used:

- Charge is halted when the battery temperature rises over a threshold.

- Charge is halted when the slope of the temperature curve rises above a threshold value.

Temperature based detection using the slope of the temperature curve is considered more accurate than voltage based detection because the detection usually happens at full SOC. The typical voltage methods need to let the cell overcharge for a certain time until the voltage drop is detected. With the temperature slope method, the full SOC detection happens closer to the optimal point.

\section{PROPOSED CHARGE CONTROL ALGORITHMS}

New, robust and reliable charge control algorithms that are suitable for charging $\mathrm{NiMH}$ batteries and Li-ion batteries with portable solar arrays are proposed. These algorithms can easily be adapted into existing battery charger IC's. For the NiMH battery, one proposed algorithm relies on the battery voltage while a second algorithm relies on the derivative of temperature. Unique to both algorithms is that they include specialized reset mechanisms to eliminate false charge termination due to changing illumination conditions, ambient temperature swings or other environmental changes. Either of these two algorithms can be used separately, but they may also be combined to improve the system robustness.

\section{(i) New Temperature Based Algorithm For Nimh}

\section{Batteries}

To improve the robustness of the charge control algorithm in changing environments, we propose a new charge control algorithm that utilizes differential measurement of temperature between battery cells. This involves separating the batteries into two (or more) groups, which we call 'legs, as they are charging inside the cradle or battery pack. 


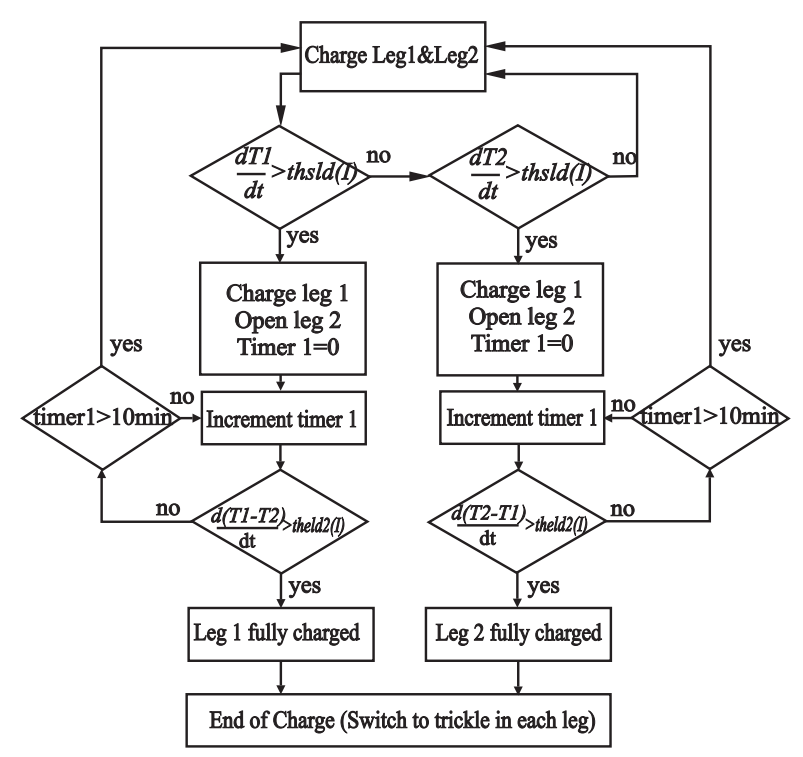

Fig. 2. Temperature based algorithm

(ii) Improved Voltage Based Algorithm

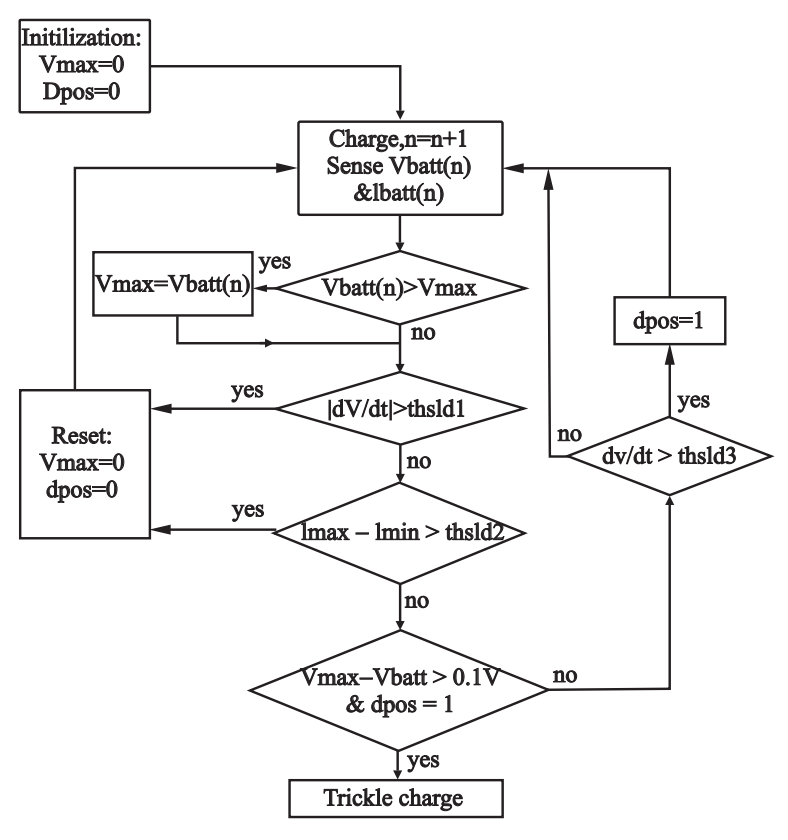

Fig. $3 \mathrm{~A}$ new proposed voltage detection algorithm.

The goal for the algorithm is not to get fooled by changing weather conditions. The idea is to keep track of the charging current and reset the algorithm whenever the current departs from an acceptable limit. This ensures that any voltage drop due to a change in the current does not falsely trigger the end of charge. This leads to the condition that if the maximum or minimum of the charging current $\left(I_{\max }, I_{\min }\right.$ on Fig. 3 , recorded over a sliding window of around 5 minutes) departs from the average value above or below a certain threshold level, the algorithm should reset. Overcharge can only be detected after the current returns to a constant value (over a period of time) again.

\section{MAXIMUM POWER POINT TRACKING (MPPT)}

A method used to harness the maximum power from a solar panel. The method is based on the Power versus Voltage characteristic of a solar panel. The point on the curve where the power is maximized is called the Maximum Power Point (MPP) of the solar panel. By inserting a DC/DC converter between the solar panel and the load, the voltage of the solar panel can be controlled to be $V_{M P P}$ and thus deliver maximum power to the load. Another advantage of this technique is that, if an up/down converter is used for the maximum power point tracker, power can then be delivered to loads with higher or lower voltage than the solar panel, enabling new applications for the same solar panel.

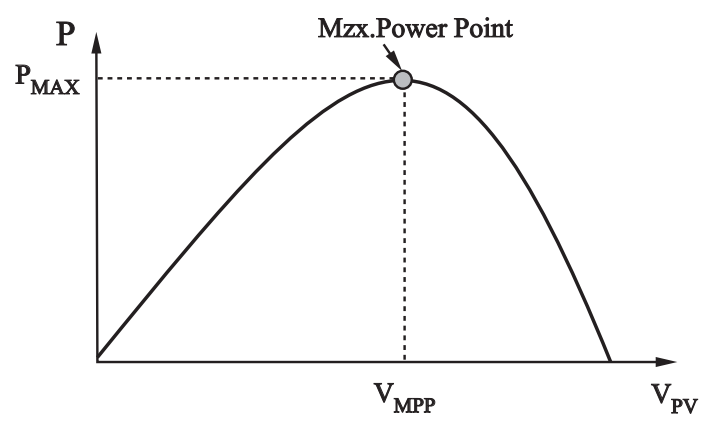

Fig.4 Power versus voltage curve of a solar panel for a given light intensity and temperature.

\section{PERTURB AND OBSERVE METHOD}

A dynamic method that seeks the Maximum PowerPoint of the solar panel and keep the panel operating around it is called the Perturb and Observe algorithm. MPPT is often realized using a Perturb \& Observe (P\&O) algorithm which is a well-known and efficient way to track the maximum power point of the solar panel.

This algorithm works by modifying the solar panel's output voltage and observing the result on the output power. If the power is increased due to the perturbation, then the algorithm keeps perturbing the 


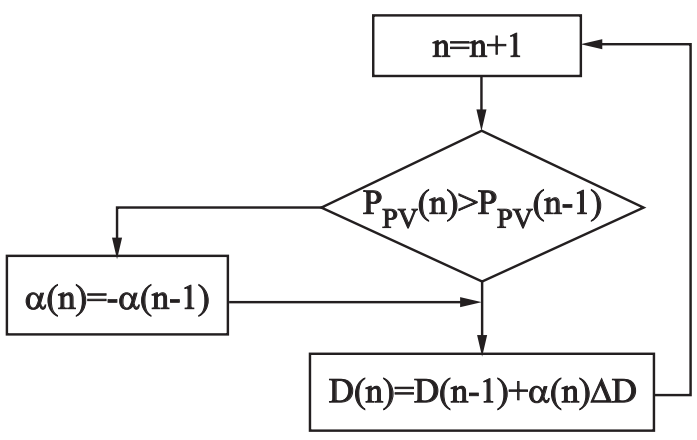

Fig. 5 Perturb \& Observe Algorithm

voltage in the same direction until the power begins to decrease. If the power decreases due to the perturbation, the algorithm reverses the direction of the perturbation. The algorithm is shown in Fig. 4. Assuming a PWM control of the switches, $D(n)$ is the duty cycle of the DC/DC converter at the sample $n . \alpha(n)$ is the direction of the perturbation at the sample $n$. Its value is either +1 or $-1 . P_{P V}(n)$ is the output power of the solar panel at the sample $n$.

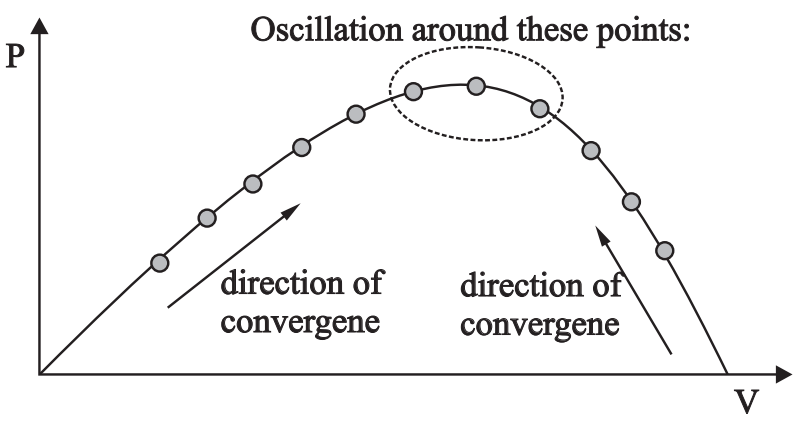

Fig. 6. Perturb \& Observe algorithm convergence

When this algorithm is applied, the solar panel will be progressively moved to its Maximum Power Point and will oscillate around it as shown in Fig.6.The advantage of the Perturb \& Observe method is that the system is able to dynamically track the maximum power point of the solar array independent of the specific solar panel technology or cell configurations. This is a major benefit over the Open Circuit Voltage method. Additionally, the system adapts to the change in the maximum power point location in real time unlike the methods described previously (including the Scanning algorithm).Generally, the input voltage is a monotonic function of the duty cycle. Hence, the Perturb \& Observe method can be applied using the input voltage reference in the DC-DC converter internal feedback voltage loop as the perturbation factor or directly the duty cycle of the DC-DC converter. The literature mentions both methods.

Normally, the Perturb and Observe method is applied using voltage and current measurements

from the solar panel. Power is then calculated from these measurements and used in the algorithm. The Perturb and Observe method can often be applied using only the output current measurement when the output voltage is relatively constant, i.e. a battery type load. This is because the output power is a function of the current and is equal to the input power if the losses in the converter are neglected.

\section{IMPROVEMENT OF MPPT THROUGH BYPASS SWITCH}

Solar panels are often manufactured to optimally charge a specific terminal battery voltage. For example, the 30W panels used in our experiments are made to charge $12 \mathrm{~V}$ batteries and have a $\mathrm{V}_{\mathrm{MPP}}$ around $14 \mathrm{~V}$. Thus, there is a range of load voltage for which MPPT actually reduces the power delivered to the battery. This is due to the power dissipation in the converter. To avoid this loss, a bypass switch can be used to create an optional direct connection between the solar panel and the battery. This reduces the losses through the system when the load voltage is matching the solar panel voltage and the bypass switch is activated. Fig.7 shows the implementation of the bypass switch in the case of a SEPIC converter: the two upper MOSFET

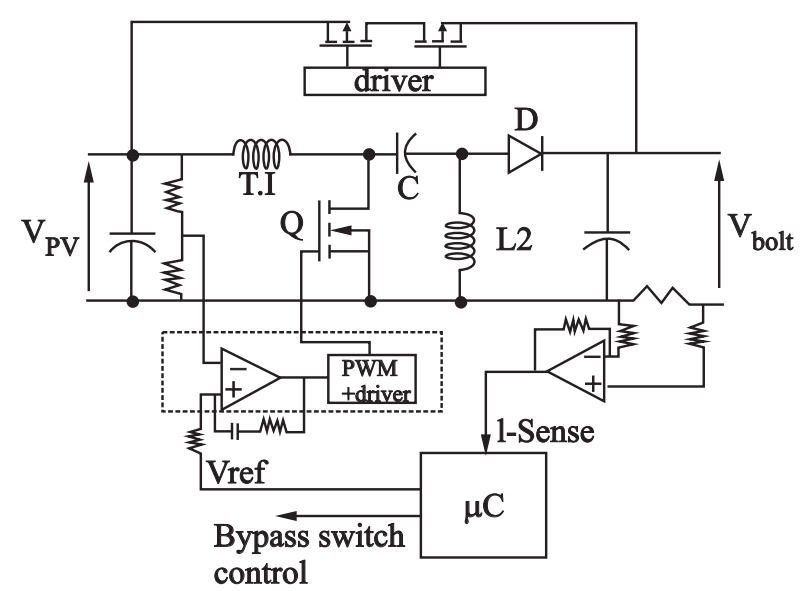

Fig.7. A Maximum Power Point Tracker with bypass switch (SEPIC topology). 
compose the bypass switch.. Fig. 8 shows an algorithm to manage the system between the two modes: direct connection and DC/DC converter operating at MPPT.

When the algorithm has stabilized around the Maximum Power Point (which is assumed to be done after a 5-s search),the micro-controller assesses whether MPPT increases delivered power or not. This is done by switching to direct connection and comparing the charging current delivered to the battery. The best solution will be retained. Every $5 \mathrm{~min}$, the two possibilities (direct connection or MPPT) will be tried again.(in case the MPP of the solar panel changed due to light intensity or temperature). The schematic of the circuit is shown in Fig. 7. $L_{1}=L_{2} 66 \mu \mathrm{H}$ $C=88 \mu \mathrm{F}, A$ is an MOSFET switching at $100 \mathrm{kHz}$ and $\mathrm{D}$ is a Schottky diode. The bypass switch consists of two series connected MOSFETs to avoid reverse current from flowing to the entry of the system, especially when the converter is working. MPPT is performed by the dc-dc converter with the bypass switch off. There is a range of load voltage for which MPPT actually reduces the power delivered to the battery. This is due to the power dissipation in the converter. To avoid this loss, the bypass switch can be used to create an optional direct connection between the solar panel and the battery. This reduces the losses through the system when the load voltage

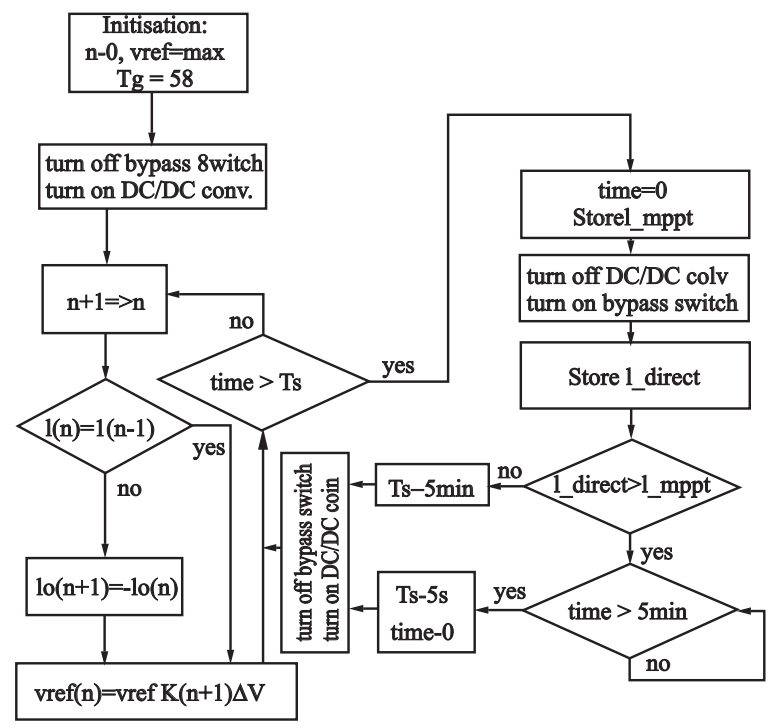

Fig. 8. An algorithm that switches between Perturbation of the DC/DC converter and direct connection between the solarpanel and the load is matching the solar panel voltage and the bypass switch is activated.

When the algorithm has stabilized around the Maximum Power Point, which is assumed to be done after a 5 second search (alternatively, the stabilization can be estimated by calculating the standard deviation of the duty cycle over a certain window of time), the micro-controller assesses whether MPPT increases delivered power or not. This is done by switching to direct connection and comparing the charging current delivered to the battery. The best solution will be retained. Every $5 \mathrm{~min}$, the two possibilities, direct connection or MPPT will be tried again. Referring to Fig. 8, $T_{s}$ is a period of time after which the algorithm is assumed to have reached the Maximum Power Point of the solar panel. After a period of $T_{S}$ has passed, the current at maximum power point, IMPPT, is stored, the DC/DC converter is momentarily turned $\mathrm{ON}$ and Maximum Power Point Tracking interrupted. The bypass switch is turned ON and the output current with bypass switch, $I_{\text {direct }}$ is compared with $I_{M P P T}$. If the output current using the bypass switch is higher than the output current achieved with the DC/DC converter using Maximum Power Point Tracking, then the bypass switch configuration is kept for a long period of time. Otherwise, the bypass switch is turned OFF and $\mathrm{DC} / \mathrm{DC}$ converter is turned $\mathrm{ON}$ again and the Maximum Power Point Tracking algorithm is re-enabled.

\section{SIMULATION RESULTS}

Simulation is done using Matlab and the results are presented. Boost converter for solar installation system is shown in Fig. 9, DC input voltage is shown in Fig. 10. Driving pulses of the MOSFET are shown in Fig. 11. Voltage across the MOSFET is shown in Fig. 12 and output current is shown in Fig. 13. DC output voltage is shown in Fig 14. Variation of output voltage with the input voltage is shown in Fig. 15. Data used for simulation studies is as follows:

$$
\begin{aligned}
& \text { Input Voltage }=5 \mathrm{~V} \\
& L_{1}=97.2 \mu \mathrm{H}, C 1=9.72 \mu \mathrm{F}, L_{2}=29.2 \mathrm{mH}, \\
& C 2=60 \mathrm{mF}, R=12 \Omega
\end{aligned}
$$




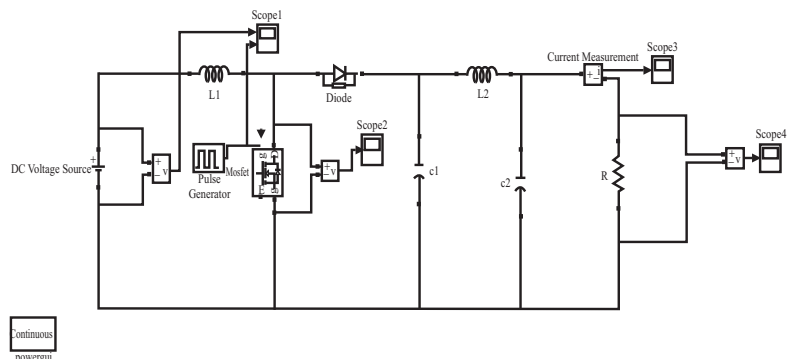

Fig. 9 Simulink circuit of open loop solar installation system

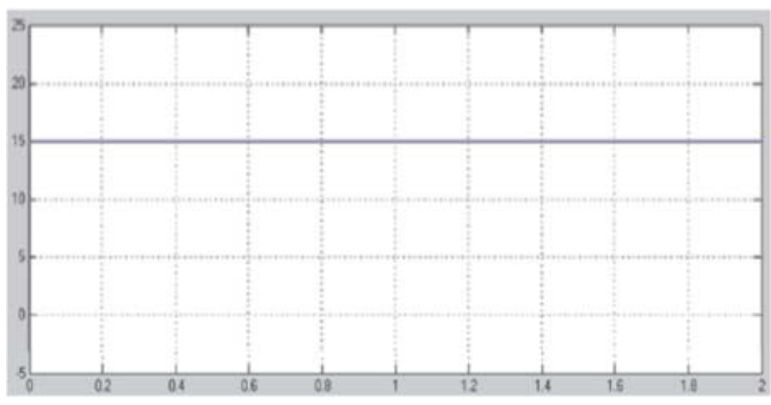

Fig. 10 Input voltage

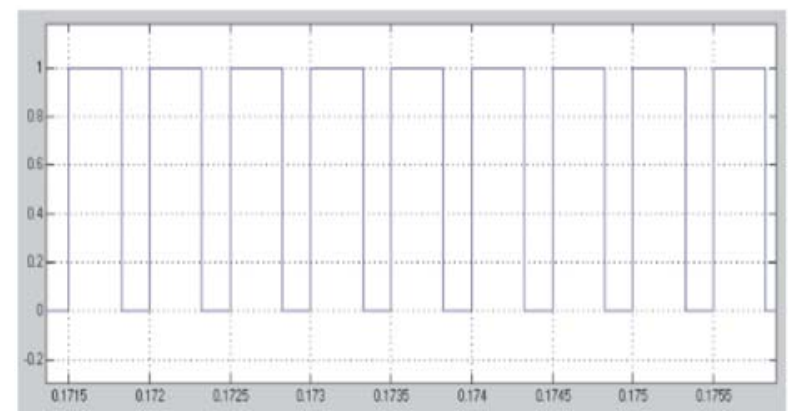

Fig. 11 Driving Pulses

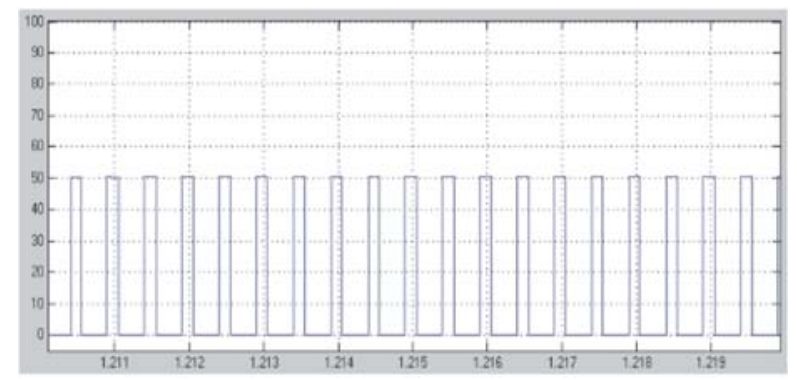

Fig. 12 Voltage across the switch

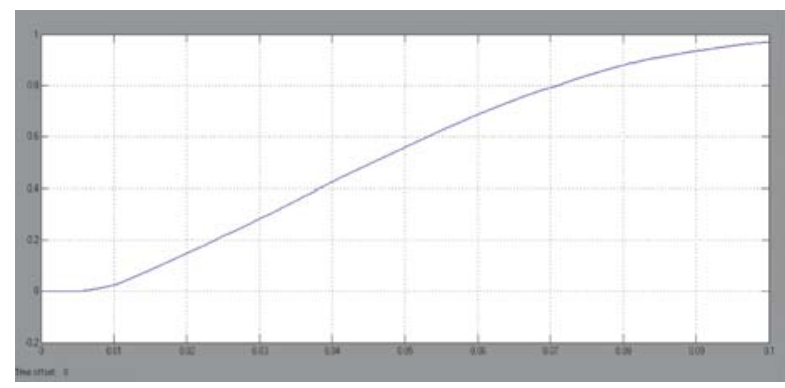

Fig. 13 Output current

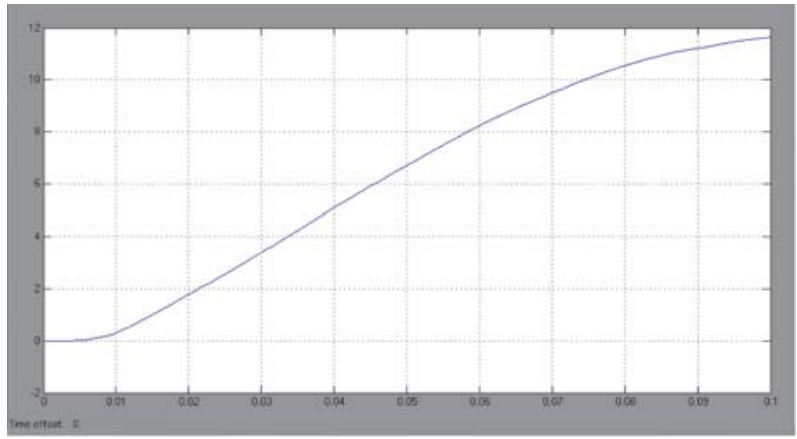

Fig. 14 DC Output voltage

Closed loop system is shown in Fig. 15. Output voltage is sensed and it is compared with a reference voltage. The error is processed by a $\mathrm{PI}$ controller, output of PI controller adjusts the pulse width to maintain the output voltage constant, input voltage and output voltage of closed loop system is shown in Fig. 16 , output voltage reduces and reaches the set value. The following equation used in PI controller is:

$$
V_{0}=k_{p} e+k_{l} \int e d t
$$

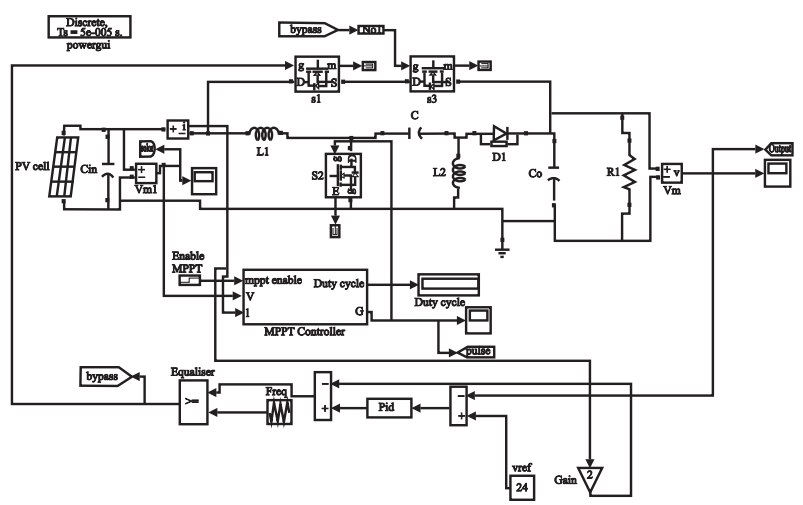

Fig. 15 Simulation circuit of closed loop solar installation system 

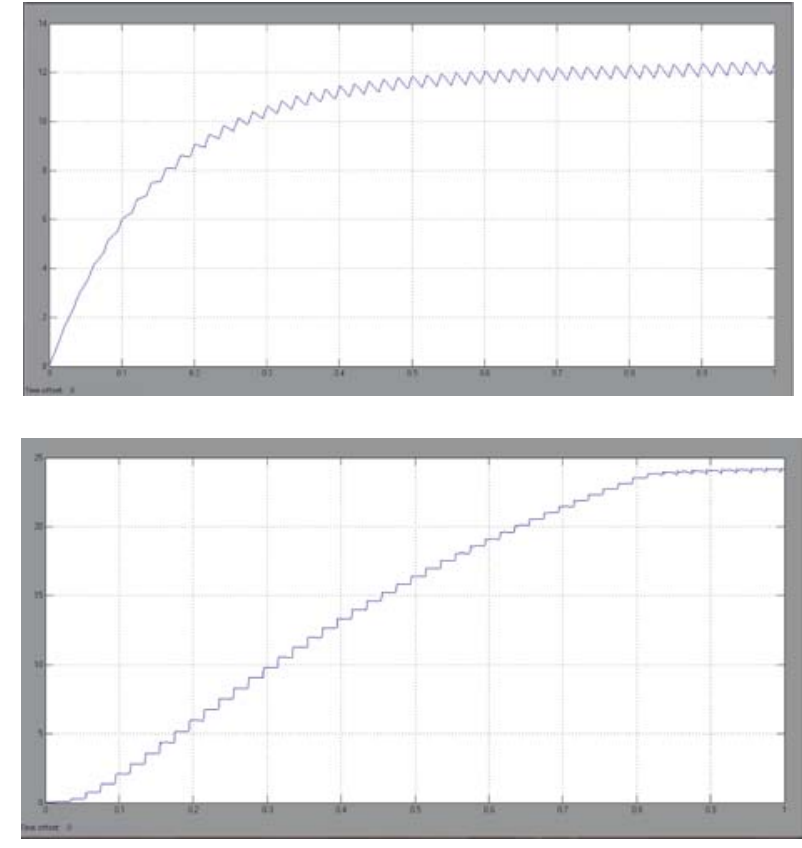

Fig. 16 Input and output voltages

\section{CONCLUSION}

Koutroulis, Kalaitzakis and Voulgaris have suggested that Maximum Power point tracking be implemented so that maximum power is obtained from the PV panel. Masoum, Badejani and Fuchs have proposed many Maximum Power Point tracking techniques .It is found that existing $\mathrm{NiMH}$ charge control algorithms fail in changing environmental conditions. The proposed project introduces charge-control algorithms which overcomes this problem. The new algorithms, Perturb \& Observe algorithms, are more robust to variations in current and temperature.

This project presents simulation of open loop and closed loop controlled boost converter system for solar installation system. MATLab models for open loop and closed loop systems are developed using the blocks of Simulink and the same are used for simulation studies.

In the proposed method, by adding a Maximum Power Point Tracker within the controller, higher charging current can be achieved.

\section{REFERENCES}

[1] Koutroulis E. and Kalaitzakis K., 2004 "Novel battery charging regulation system for photovoltaic applications," Proc. Inst. Elect. Eng., vol. 151,no. 2, pp. 191-197,.

[2] Koutroulis E., Kalaitzakis K., and Voulgaris N. C. , 2001 "Development of a microcontroller-based, photovoltaic maximum power point tracking control system," IEEE Trans. Power Electron., vol. 16, no. 1, pp. $46-54$,.

[3] Masoum M. A. S., Mosavi S. M., and Fuchs E. F., 2004 "A Microprocessor controlled new class of optimal battery chargers for photovoltaic applications," IEEE Trans. Energy Convers., vol. 19,no. 3, pp. 599-606,.

[4] Boico, Florent Michael, "Improving battery charging with solar panels" 2008. Electrical Engineering Dissertations. Paper 9. http://hdl.handle.net/2047/ d10017999

[5] Gonzalez M., Ferrero F. J., Anton J. C., and Perez M. A., 1999,"Considerations to improve the practical design of universal and full-effective $\mathrm{NiCd} / \mathrm{NiMH}$ battery fast-chargers," in Applied Power Electronics Conf. and Expo., vol. 1, pp. 167-173.

[6] Lima F., Ramalho J.N., Tavares D., Duarte J., Albuquerque C., Marques T., Geraldes A., Casimiro A. P., Renkema G., Been J., and Groeneveld W., 2003, "A novel universal battery charger for NiCd, NiMH, Li-ion and Li-polymer," in Proc. Conf. Eur. Solid-State Circuits, pp. 209-212.

[7] http/::www.batterystuff.com/files/scc30ab_ manual_feb2011.pdf. 